\title{
The Influence of Voluntary Service Activities on Self-Esteem and Communication Skills among Korean University Students in Healthcare and Medical Fields
}

\author{
Se-Won Kang* \\ Department of Nursing, Dongseo University, 47 Jurye-ro, Sasang- \\ gu, Busan 47011, South Korea.
}

${ }^{*}$ Corresponding author

Se-Won Kang, Department of Nursing, Dongseo University, 47 Juryero, Sasang-gu, Busan 47011, South Korea, Tel: +82-51-320-2862; Fax: +82-51-320-2721; E-mail: swkang75@hotmail.com.

Submitted: 17 Jan 2017; Accepted: 26 Jan 2017; Published: 30 Jan 2017

\begin{abstract}
Objectives: This is a descriptive study intended to investigate characteristics of voluntary service activities of university students in healthcare and medical fields and to examine the influence of voluntary service activities on self-esteem and communication.
\end{abstract}

Methods: Data collection for this study continued from July to August 2015, and 200 universities located at B city in Korea who majored in healthcare and medical fields (nursing, physical therapy, occupational therapy, dental hygiene, radiology, clinical pathology). The collected data were analyzed using the PASW Statistics 18.0 program.

Results: The results showed that $68.3 \%$ of participants indicated that their self-esteem increased after voluntary service activities while $70.1 \%$ of participants indicated that their communication skills improved. Self-esteem scores based on participants' characteristics varied depending on voluntary service participation attitude ( $p=$ $0.001)$, teamwork $(p=0.005)$, extent of feeling worthwhile $(p=0.039)$, and satisfaction with voluntary service $(p<0.001)$. Additionally, communication skill scores varied depending on voluntary service activity experience $p=$ $0.005)$, voluntary service participation attitude $(p<0.001)$, teamwork $(p=0.001)$, extent of feeling worthwhile $(p$ $=0.002)$, and satisfaction with voluntary service $(p<0.001)$.

Conclusions: The results suggested that voluntary service activities could improve self-esteem and communication skills in university students. Influential variables included voluntary service activity experience, voluntary service participation attitude, teamwork, extent of feeling worthwhile, and satisfaction with voluntary service. There is a need to develop and promote various voluntary service programs tailored to university students that can motivate them to participate in voluntary service activities positively and actively, and to induce them to be engaged continuously in voluntary service activities.

Keywords: Communication skills, Voluntary service activities, Self-esteem.

\section{Introduction}

It is important to cultivate the right personal morality necessary to resolve various problems facing modern society to restore humanity and promote social skill essential for building proper relations with various kinds of people and living with them in harmony. In addition, individuals need to develop valued job skills necessary for economic participation. Individuals are confronted with challenges of making novel efforts to properly adapt themselves to society and overcome ever-increasing individualism. Among others, there has been a need for activities that can maximize creativity and spontaneity in the process in which individuals strive to achieve their goals. Voluntary service activities are manifested by such personal efforts [1-2].

Many university students participate in voluntary service activities.
University students' voluntary service activities have a significant impact on their future lives, considering that the university years represent a meaningful period for finalizing adolescent development and preparing for life as a member of society [3]. As universities are showing a heightened interest in university students' voluntary service activities and realizing the need for such activities, voluntary service activities have been increasingly integrated into compulsory courses or have become an essential requirement for graduation. A survey conducted by the Korean University Council for Social Service (KUCSS) in 2009 showed that 138 universities, which comprised $81 \%$ of 169 universities affiliated with the KUCSS, offered social service participation as part of the curriculum [4]. The university years represent a period of transition from adolescence to adulthood and therefore require the most extensive adaptation to physical, psychological, and environmental changes. Self-esteem is vital in establishing values and beliefs in the adaptation to such changes and interactions with new people [5]. Self-worth and self-esteem are participative and 
continue to develop and have influence throughout life.

If high self-esteem is formed in university students who need to adapt themselves to the process of being integrated into society, they can feel themselves worthy, mature, respectful towards themselves, and confident, and become responsible adults [6]. It is important for university students to adapt themselves to new changes; however, they do have increased opportunities for interaction in their interpersonal relationships with people that they meet in society. Communication skills are needed for smooth and undisrupted interactions with new people. Moreover, communication skills are closely associated with comprehension of situations or social circumstances and area factor required for university students preparing to become members of society [7-8].

In particular, university students in healthcare and medical fields are expected to play a role as specialized human resources who are equipped with communication skills and problem-solving abilities to provide high quality healthcare and medical services to promote public health. Therefore, voluntary social service experience, self-worth, and ability to communicate with others are especially required for university students in healthcare and medical fields.

Previous Korean studies on voluntary service activities of university students covered current status and promotion of voluntary service activities, participation influence factors, sustainability determinant factors, participation motives, extent of satisfaction, and awareness and participation attitude as basic investigations of voluntary service activities [9-13]. However, few studies have specifically addressed how voluntary service activities of university students affect individuals' internal and external characteristics and growth. Although previous studies have investigated the relationship of voluntary service activities with self-development and sociality and the relationship between self-esteem and self-efficacy, there have been only a few related studies and there have been no studies on communication skills vital for specific expressions of sociality $[6,14]$. Particularly, there is a lack of studies examining the relationships of voluntary service activities with socio-psychological variables among university students in healthcare and medical fields.

Thus, this study intended to shed light on the importance and true meaning of voluntary service activities of university students by examining the characteristics of voluntary service activities of university students in healthcare and medical fields and determining the effects that the characteristics of such activities would have on self-esteem and communication skills.

\section{Purpose of Study}

The purpose of this study was to investigate characteristics of voluntary service activities among university students in healthcare and medical fields and to examine the influence of voluntary service activities on self-esteem and communication. Specific objectives of this study are as follows:

(1) Investigate the characteristics of voluntary service activities of participants.
(2) Examine improvements in self-esteem and communication skills after voluntary service activities.

(3) Determine self-esteem and communication skills, depending on characteristics of participants

\section{Materials and Method}

Study design

This is a descriptive study intended to investigate characteristics of voluntary service activities of university students in healthcare and medical fields and to examine the effect of voluntary service activities on self-esteem and communication.

\section{Study participants}

The participants were 219 students in universities located at B city in Korea who majored in healthcare and medical fields (nursing, physical therapy, occupational therapy, dental hygiene, radiology, clinical pathology) and participated in the survey with understanding of the purpose of this study. The results obtained from 200 participants were used for data analysis, excluding 19 questionnaires containing insincere answers.

\section{Ethical considerations for data collection}

Data collection for this study occurred from July to August 2015. To collect the data, the research assistants met the participants directly and explained the purpose and meaning of the research. The front page of the questionnaire included information, such as the study title, the researcher's contact information, a statement that there would be no disadvantage from refusal to participate, that anonymity was guaranteed, and that the information provided by them would not be used for any purpose other than for this study. Data were collected only from participants that voluntarily provided written consent. The questionnaires were distributed to participants who provided consent to participate. Participants were instructed to fill out the questionnaires by themselves before they were collected. Questionnaires took 10 minute to complete.

\section{Study Instruments}

\section{Self-Esteem}

For the self-esteem tool, we used the tool of as standardized by as a Korean version [15-16]. The questionnaire consists of 10 items that comprise 5 affirmative self-esteem items and 5 negative selfesteem statements. We used a4-point Likert scale anchored with 1 point = "almost not so" to 4 points = "always so." Negative items were reverse-coded. Higher scores indicate higher self-esteem. Regarding there liability of the tool, at the time of its development Cronbach's alpha was 0.850 , while in this study it was 0.814 .

\section{Communication Skills}

The communication skills tool used in this study was Global Interpersonal Communication Competence Scale [17]. This tool consists of 15 items: self-exposure, empathy, social tension relief, claiming ability, interaction management, expressive power, supporting ability, immediacy, other person orientation, concentration, efficiency, social appropriateness, logicality, intention detection, reactive power, and noise control. As a5-point Likert scale was used, higher scores meant higher communication 
skills. Regarding there liability of the tool, at the time of its development Cronbach's alpha 0.720 , while in this study it was 0.860 .

Improvements in Self-Esteem and Communication Skills after Voluntary Service Activities

To evaluate improvements in participants' self-esteem and communication skills after voluntary service activities, we used 1 item scales related to self-esteem and to communication skills respectively, anchored by the terms "improved very much,"“improved," "improved moderately," and "not improved."

\section{Data Analysis}

The collected data were analyzed using the PASW Statistics 18.0 program. Specific analysis methods used for the variables were as follows. 1) Participants' characteristics were estimated using the frequency, percentage, mean, and standard deviation. 2) The extent of improvements in self-esteem and communication skills after voluntary service activities were analyzed through frequencies and percentages. 3) The differences in self-esteem and communication skills, depending on participants' characteristics, were analyzed through independent t-tests and ANOVA. For the inter-group post-test of ANOVA, Scheffe's analysis was used. 4) Statistical significance was estimated at 0.05 .

\section{Results}

\section{Characteristics of participants}

The total number of study participants used in the data analysis was 200 , consisting of 131 women $(65.5 \%)$ and 69 men (34.5\%). The mean age was 21 . By grade, there were 53 freshmen (26.5\%), 46 sophomores (23.0\%), 70 juniors (35.0\%), and 31 seniors (15.5\%).

A total of 164 participants $(82.0 \%)$ had experience with voluntary service activities. The average number of voluntary service activities was determined to be as follows: once per month $(15.9 \%)$; twice per month $(8.5 \%)$; 1 to 3 times per week $(9.8 \%)$; and on an irregular basis $(65.9 \%)$. For the location of voluntary service activities, domestic locations comprised 79.0\% and overseas locations comprised $13.0 \%$. Overseas locations of voluntary service activities included Cambodia, the Philippines, Indonesia, etc.

Fifty percent of participants were engaged in voluntary service activities related to their majors; $54.9 \%$ of participants, the highest proportion, were found to have volunteered in the elderly welfare sector. For the motives of voluntary service activities participation, $51.8 \%$ of participants, the highest proportion, answered that the motive was to help others. For the attitude to voluntary service activities, participants who answered "participate actively" comprised $51.8 \%$. For teamwork, $59.1 \%$ of participants answered "largely satisfied." For the extent of feeling worthwhile for participation in service activities, $53.0 \%$ of participants answered "feel more or less worthwhile." For the extent of satisfaction with voluntary service activities, $62.2 \%$ of participants answered "feel satisfied" (Table 1).

J Nur Healthcare, 2017

\begin{tabular}{|c|c|c|c|}
\hline \multicolumn{2}{|c|}{ Variables } & $\mathbf{n}$ & $(\%)$ \\
\hline \multirow{2}{*}{$\begin{array}{l}\text { Gender- Age: } 21.3 \pm 2.19 \\
\text { (range 18-30) }\end{array}$} & Women & 131 & $(65.5)$ \\
\hline & Men & 69 & $(34.5)$ \\
\hline \multirow{4}{*}{ Grade } & Freshmen & 53 & $(26.5)$ \\
\hline & Sophomore & 46 & $(23.0)$ \\
\hline & Junior & 70 & $(35.0)$ \\
\hline & Senior & 31 & $(15.5)$ \\
\hline \multirow{2}{*}{$\begin{array}{l}\text { Experience or non- } \\
\text { experience with voluntary } \\
\text { service activities }\end{array}$} & Experienced & 164 & $(82.0)$ \\
\hline & Not experienced & 36 & $(18.0)$ \\
\hline \multirow{4}{*}{$\begin{array}{l}\text { Average frequency of } \\
\text { voluntary service activities } \\
\text { during university years }{ }^{\mathrm{a}}\end{array}$} & Month a month & 26 & $(15.9)$ \\
\hline & Twice a month & 14 & $(8.5)$ \\
\hline & 1 to 3 times a week & 16 & $(9.8)$ \\
\hline & On an irregular basis & 108 & $(65.9)$ \\
\hline \multirow{3}{*}{$\begin{array}{l}\text { Location of voluntary } \\
\text { service activities: Korea }\end{array}$} & Korea & 158 & $(79.0)$ \\
\hline & Overseas countries $^{\mathrm{c}}$ & 26 & $(13.0)$ \\
\hline & Korea \& overseas countries & 20 & $(10.0)$ \\
\hline \multirow{2}{*}{$\begin{array}{l}\text { Relationship between } \\
\text { voluntary service activities } \\
\text { and major }{ }^{\mathrm{a}}\end{array}$} & Related with major & 82 & $(50.0)$ \\
\hline & Not related with major & 82 & $(50.0)$ \\
\hline \multirow{7}{*}{$\begin{array}{l}\text { Field of voluntary service } \\
\text { activities }^{\text {b }}\end{array}$} & $\begin{array}{l}\text { Welfare of children and } \\
\text { adolescents }\end{array}$ & 71 & $(43.3)$ \\
\hline & Field of voluntary service & 90 & $(54.9)$ \\
\hline & activities $^{\mathrm{b}}$ & 40 & $(24.4)$ \\
\hline & Transportation and environment & 10 & $(6.1)$ \\
\hline & Counselling and education & 15 & $(9.1)$ \\
\hline & Medical & 43 & $(26.2)$ \\
\hline & Administrative support & 19 & (11.6) \\
\hline \multirow{8}{*}{$\begin{array}{l}\text { Motives for participation in } \\
\text { voluntary service activities }\end{array}$} & To help others & 85 & $(51.8)$ \\
\hline & $\begin{array}{l}\text { For my growth and } \\
\text { development }\end{array}$ & 76 & $(46.3)$ \\
\hline & For credits and employment & 67 & $(41.2)$ \\
\hline & For interpersonal relationship & 32 & $(19.5)$ \\
\hline & For religious reasons & 19 & (11.6) \\
\hline & $\begin{array}{l}\text { To experience various types } \\
\text { of life }\end{array}$ & 66 & $(40.2)$ \\
\hline & Due to interest in social issues & 13 & ( 7.9$)$ \\
\hline & For satisfactory leisure & 28 & $(17.1)$ \\
\hline \multirow{3}{*}{$\begin{array}{l}\text { Attitude towards voluntary } \\
\text { service activities }\end{array}$} & Participate very actively & 49 & (29.9) \\
\hline & Participate actively & 85 & $(51.8)$ \\
\hline & Participate moderately & 30 & (18.3) \\
\hline \multirow{3}{*}{$\begin{array}{l}\text { Teamwork with people } \\
\text { carrying out voluntary } \\
\text { service activities }\end{array}$} & Satisfied greatly & 43 & $(26.2)$ \\
\hline & Satisfied largely & 97 & $(59.1)$ \\
\hline & Moderately & 24 & (14.6) \\
\hline \multirow{3}{*}{$\begin{array}{l}\text { Extent of feeling worthwhile } \\
\text { during participation in } \\
\text { voluntary service activities }\end{array}$} & Feel worthwhile greatly & 63 & $(38.4)$ \\
\hline & Feel worthwhile more or less & 87 & $(53.0)$ \\
\hline & Moderately & 14 & $(8.5)$ \\
\hline \multirow{3}{*}{$\begin{array}{l}\text { Extent of satisfaction with } \\
\text { voluntary service activities }\end{array}$} & Satisfied greatly & 40 & (24.4) \\
\hline & Satisfied largely & 102 & $(62.2)$ \\
\hline & Moderately & 22 & (13.4) \\
\hline
\end{tabular}

Table 1: Characteristics of participants $(\mathrm{N}=200)$.

aAnswers provided only by participants having experience with voluntary 
service activities

${ }^{\mathbf{b}}$ Multiple responses among participants having experience with voluntary service activities.

'Overseas location of voluntary service activities, Country(n): Cambodia (12), Africa (Ghana) (1), Philippines (10), Canada (1), USA (1), Indonesia (3), Myanmar (1), Tajikistan (1), Germany (1), France (1), Costa Rica (1), Vietnam (1), Japan (1).

Improvements in Self-Esteem and Communication Skill after Voluntary service Activities

For the extent of improvement in self-esteem after voluntary service activities, $68.3 \%$ answered 'improved very much', 25.6\%answered 'improved moderately' and 6.1\%answered 'not improved'.

For the extent of improvement in communication skill after voluntary service activities, those who answered 'improved very much', 'improved moderately' and 'not improved', comprised $70.1 \%, 22.6 \%$, and $7.3 \%$ respectively (Table 2 ).

\begin{tabular}{|c|c|c|c|}
\hline Variables & n & $(\mathbf{\%})$ \\
\hline \multirow{2}{*}{$\begin{array}{c}\text { Extent of improvement in } \\
\text { self-esteem after voluntary } \\
\text { service activities }\end{array}$} & Improved very much & 112 & $(68.3)$ \\
\cline { 2 - 4 } & Improved moderately & 42 & $(25.6)$ \\
\cline { 2 - 4 } & Not improved & 10 & $(6.1)$ \\
\hline \multirow{2}{*}{$\begin{array}{c}\text { Extent of improvement in } \\
\text { communication skill after } \\
\text { voluntary service activities }\end{array}$} & Improved very much & 115 & $(70.1)$ \\
\cline { 2 - 4 } & Improved moderately & 37 & $(22.6)$ \\
\cline { 2 - 4 } & Not improved & 12 & $\mathbf{( 7 . 3 )}$ \\
\hline
\end{tabular}

Table 2: Improvements in self-esteem and communication skills after voluntary service activities $(\mathrm{N}=164)$.

Self-Esteem and Communication Skills According to Participants' Characteristics

The mean score on self-esteem was 3.08 (out of a maximum score of 4 points), and the mean score on communication skills was 3.73 (out of a maximum score of 6).

Variables that showed significant differences in self-esteem or communication skills, depending on participants' characteristics, are presented in Table 3. The self-esteem score based on participants' characteristics varied, depending on service participation attitude $(\mathrm{F}=7.323, \mathrm{p}=0.001)$, teamwork $(\mathrm{F}=5.440$, $\mathrm{p}=0.005)$, extent of feeling worthwhile $(\mathrm{F}=3.302, \mathrm{p}=0.039)$, and satisfaction with service $(\mathrm{F}=9.783, \mathrm{p}<0.001)$. The communication skills score based on participants' characteristics varied, depending on voluntary service experience $(\mathrm{t}=2.810, \mathrm{p}=0.005)$, service participation attitude $(\mathrm{F}=10.808, \mathrm{p}<0.001)$, teamwork $(\mathrm{F}=7.529$, $p=0.001)$, extent of feeling worthwhile $(F=6.541, p=0.002)$, and satisfaction with service $(\mathrm{F}=10.410, \mathrm{p}<0.001)$.

\begin{tabular}{|c|c|c|c|c|}
\hline \multirow{2}{*}{ Variables } & \multicolumn{2}{|c|}{ Self-Esteem Score } & \multicolumn{2}{|c|}{$\begin{array}{c}\text { Communication skill } \\
\text { Score }\end{array}$} \\
\cline { 2 - 5 } & $\begin{array}{c}\text { Mean (SD) } \\
(\min 1-\max 4)\end{array}$ & $\mathrm{t}$ or $F(p)$ & $\begin{array}{c}\text { Mean }(\mathrm{SD}) \\
(\min 1-\max 5)\end{array}$ & $\mathrm{t}$ or $F(p)$ \\
\hline Total & $\begin{array}{c}3.08(0.45) \\
\text { range } \\
(1.80-3.90)\end{array}$ & & $\begin{array}{c}3.73(0.46) \\
\text { range } \\
(2.27-5.00)\end{array}$ & \\
\hline
\end{tabular}

J Nur Healthcare, 2017

\begin{tabular}{|c|c|c|c|c|c|}
\hline \multirow{2}{*}{$\begin{array}{c}\text { Voluntary } \\
\text { service } \\
\text { experience }\end{array}$} & Experienced & $3.09(0.44)$ & \multirow{2}{*}{$\begin{array}{c}0.636 \\
(0.526)\end{array}$} & $3.77(0.48)$ & \multirow{2}{*}{$\begin{array}{c}2.810 \\
(0.005)\end{array}$} \\
\hline & Not experienced & $3.04(0.51)$ & & $3.54(0.36)$ & \\
\hline \multirow{3}{*}{$\begin{array}{c}\text { Attitude of } \\
\text { participation } \\
\text { in voluntary } \\
\text { service }\end{array}$} & ${ }^{a}$ Very actively & $3.21(0.38)$ & \multirow{3}{*}{$\begin{array}{c}7.323 \\
(0.001) \\
* a>c \\
(p<0.001) \\
* b>c \\
(p=0.009)\end{array}$} & $3.96(0.52)$ & \multirow{3}{*}{$\begin{array}{c}10.808 \\
(<0.001) \\
* a>c \\
(p=0.001) \\
* b>c \\
(p=0.009\end{array}$} \\
\hline & ${ }^{\mathrm{b}}$ Actively & $3.12(0.42)$ & & $3.77(0.42)$ & \\
\hline & 'Moderately & $2.84(0.50)$ & & $3.48(0.42)$ & \\
\hline \multirow{3}{*}{ Teamwork } & aSatisfied greatly & $3.24(0.40)$ & \multirow{3}{*}{$\begin{array}{c}5.440 \\
(0.005) \\
*_{a}>c \\
(p=0.005)\end{array}$} & $3.99(0.50)$ & \multirow{3}{*}{$\begin{array}{c}7.529 \\
(0.001) \\
* a>b \\
(\mathrm{p}=0.014) \\
* a>c \\
(\mathrm{p}=0.002)\end{array}$} \\
\hline & ${ }^{\mathrm{b}}$ Satisfied largely & $3.09(0.39)$ & & $3.74(0.38)$ & \\
\hline & ${ }^{\circ}$ Moderately & $2.87(0.60)$ & & $3.56(0.66)$ & \\
\hline \multirow{3}{*}{$\begin{array}{l}\text { Extent of } \\
\text { feeling } \\
\text { worthwhile }\end{array}$} & $\begin{array}{c}{ }^{\mathrm{a}} \text { Feel worthwhile } \\
\text { greatly }\end{array}$ & $3.18(0.36)$ & \multirow{3}{*}{$\begin{array}{c}3.302 \\
(0.039)\end{array}$} & $3.91(0.43)$ & \multirow{3}{*}{$\begin{array}{c}6.541 \\
(0.002)\end{array}$} \\
\hline & $\begin{array}{c}{ }^{\mathrm{b}} \mathrm{Feel} \text { worthwhile } \\
\text { largely }\end{array}$ & $3.07(0.46)$ & & $3.73(0.47)$ & \\
\hline & 'Moderately & $2.85(0.57)$ & & $3.44(0.48)$ & \\
\hline \multirow{3}{*}{$\begin{array}{l}\text { Satisfaction } \\
\text { with } \\
\text { voluntary } \\
\text { service }\end{array}$} & aSatisfied greatly & $3.14(0.39)$ & \multirow{3}{*}{$\begin{array}{c}9.783 \\
(<0.001) \\
* a>c \\
(p=0.001) \\
* b>c \\
(p=0.001)\end{array}$} & $3.98(0.46)$ & \multirow{3}{*}{$\begin{array}{c}10.410 \\
(<0.001) \\
*_{a}>c \\
(p<0.001) \\
* b>c \\
(p=0.007)\end{array}$} \\
\hline & ${ }^{\mathrm{b}}$ Satisfied largely & $3.16(0.40)$ & & $3.77(0.44)$ & \\
\hline & 'Moderately & $2.72(0.56)$ & & $3.43(0.48)$ & \\
\hline
\end{tabular}

Table 3: Participants' characteristics and scores on self-esteem and communication skills. *Scheffé's test.

\section{Discussion}

Many university students were found to participate in voluntary service activities to pave the way for their internal growth and social activities during their university years, the early period of adulthood. As voluntary service activities are diversified, expanding into various realms, and gathering momentum, we intended to explore the true meaning and value of voluntary service activities for university students in healthcare and medical fields.

\section{Characteristics of Participants}

Among the participants in this study, more than $80 \%$ experienced voluntary service activities, reflecting an increase in the number of university student volunteers. Moreover, most participants engaged in voluntary service activities on an irregular basis, which could be attributed to the fact that they participated in voluntary service activities during their leisure time as they were mainly studying due to the demands of university life. For the location of voluntary service activities, most participants were engaged in voluntary service activities at domestic locations. About $15 \%$ of Participants engaged in voluntary service activities at overseas locations. This reflected the preference for locations easily accessible for voluntary service activities. Moreover, voluntary service activities were performed at various overseas locations in more than 13 countries, suggesting that the scope of voluntary service activities was broadening. For correlations between voluntary service activities and major, the participants were found to select from a wide scope of voluntary service activities, regardless of their majors.

The largest numbers of participants were engaged in voluntary service activities in the elderly welfare sector, which implied that the need for voluntary service activities was high in this field. 
For the motives of participation in voluntary service activities, motives for helping others comprised the highest proportion, followed by motives for self-growth and self-development, those for credits or employment, and those for experiencing various types of lives. This result was consistent with that of a study conducted by that showed that the motives for participation in voluntary service activities among university students were primarily the desire to understand others, self-improvement, value motivation, and social motivation [12]. It can be understood in the context that voluntary service activities are instrumental in increasing understanding of others, strengthening the sense of responsibility, expanding work experience and self-discipline, etc., which are necessary for social life and employment.

Participants mostly reported that they were actively engaged in voluntary service activities and were satisfied in connection with their attitude towards voluntary service activities, teamwork, extent of feeling worthwhile, extent of satisfaction, and awareness of the need for voluntary service activities. This suggested that the value of voluntary service activities might vary, depending on the extent of participation in voluntary service activities.

Improvements in Self-Esteem and Communication Skills after Voluntary Service Activities

Self-esteem and communication skills were reported to have improved after voluntary service activities, consistent with the results of a study conducted by that suggested that voluntary service activities of university students had a positive effect on self-esteem and social skills [8]. Additionally, this was consistent with the results of a study conducted by that suggested that scores of both self-esteem and self-efficacy increased after participation in voluntary service [6]. Additionally, this was consistent with the result of studies conducted by that showed improvements in autonomy, leadership, sociability, and serviceability in students due to the effect of a voluntary service activity program applying social interaction skills that emphasized skills in communication, relationship building, and self-expression [18].

Characteristics of Participants Related to Self-Esteem and Communication Skills

Self-esteem scores based on participants' characteristics were higher when service participation attitude was positive, when teamwork was satisfactory, and when extent of feeling worthwhile and satisfaction with service were higher. These results are consistent with those of a study conducted by suggesting that university students' voluntary service activities alone did not have an influence but that the contents and significance of voluntary service activities, corresponding to various areas of psychological satisfaction after implementation of voluntary service activities, were important [14].

The communication skills scores based on participants' characteristics were higher among participants having experience with voluntary service activities. Communication skills tended to be higher when service participation attitude was more active, when teamwork was more satisfactory, and when extent of feeling worthwhile and satisfaction with service were higher. Particularly, the experience with voluntary service activities had an influence on communication skills, which was consistent with the result of a study conducted by showing that experience or non-experience with voluntary service activities affected social skills [3]. This means that various content factors of voluntary service activities can affect communication, suggesting that participants themselves need to participate actively.

\section{Study limitations}

This study is limited in that the data were collected through convenience sampling, and therefore care needs to be taken when generalizing the meaning of the results of this study. Succeeding studies need to use repetitive research involving larger number of participants.

\section{Conclusion}

University students are currently required to carry out various external activities. These activities include voluntary service activities, and university students tend to participate passively without realizing the benefits of voluntary service activities for themselves. This study was intended to determine the significance and meaning of voluntary service activities of university students. The results of this study showed that voluntary service activities could help increase self-esteem needed to perceive self-worth and help build communication skills for smooth and undisrupted interactions with others, and also suggested that content factors of various voluntary service activities had an influence.

For university students in healthcare and medical fields who have a mission for national healthcare, voluntary service activities can serve as a basis for improving self-worth and interpersonal communication skills, thus helping lay the groundwork for developing themselves into specialized medical workers. University students should be induced to expose themselves to a variety of voluntary service activities and increase their participation. In addition, various social voluntary service activity programs and supportive systems need to be designed and built to ensure that university students participate actively with initiative and continue their participation.

\section{References}

1. O'toole TP, Hanusa BH, Gibbon JL, Boyles SH (1999) Experiences and attitudes of residents and students influence voluntary service with homeless populations. J Gen Intern Med 14: 211-216.

2. Schmidt JA, Shumow L, Kackar HZ (2012) Associations of participation in service activities with academic, behavioral, and civic outcomes of adolescents at varying risk levels. J Youth Adolesc 4: 932-947.

3. Loh AZ, Tan JS, Lee JJ, Koh GC (2016) Voluntary community service in medical school: A qualitative study on student leaders' motivations, experiences, and outcomes. Med Teach 38: 683-690.

4. Korean University Council for Social Service (KUCSS) (2009) Mid-term abroad volunteer group report, Hearts together.

Volume 2 | Issue $1 \mid 5$ of 6 
Happy Sharing and Service Seoul: Korean University Council for Social Service.

5. Haq MA (2016) Association between Socio-Demographic Background and Self-Esteem of University Students. Psychiatr Q 87: 755-762.

6. Park SY, Kim JK, Lee TY (2011) Effect of occupational therapy volunteering on self-esteem and self-efficiency in university students, J Korea Cont Soc 11: 376-384.

7. Shah S, Andrades M, Basir F, Jaleel A, Azam I, et al. (2016) Has the inclusion of a longitudinally integrated communication skills program improved consultation skills in medical students? A pilot study. J Family Med Prim Care 5: 45-50.

8. Mckinney KG (2002) Engagement in community service among college students: is it affected by significant attachment relationships? J Adolesc 25: 139-154.

9. Oh J, Ah YA (2007) A study on actual condition and activation for volunteering activities of the university students - focused on university students in pusan city. JSoc Welfare Devel 13: 31-53.

10. Kim W, Song MY (2006) A Study on factors affecting the participation level of volunteer activities among the college Students. Korean J Youth Stud 13: 330-380.

11. Hong YS (2002) Determinants influencing voluntary action continuity of college student volunteers. J Adol Welfare 4: 7597.
12. Cho SY, Park JH, Lee H (2011) A Study on volunteers` motivation and satisfaction of college student volunteers as leisure. J Sport Sci 18: 23-32.

13. Kim W (2011) the relationships between volunteer education, importance recognition, and participation attitudes of volunteer activities among college students. Korean J Youth Stud 18:301-329.

14. Hu SH, Jung TY (2013) Effects of volunteer activities on selfdevelopment and sociability-development of undergraduates: focus on meaning of volunteering. J Korean Psychol Associ 19: 133-158.

15. Rosenberg M (1965) Society and adolescent self-image. Princeton, NJ: Priceton University Press.

16. Jeon BJ (1974) Self-esteem: a test of its measurability. Yonsei Nonchong 11: 107-129.

17. Huh GH (2003) Construction and validation of a global interpersonal communication competence scale, Korean J Journal Communication Stud 47: 308-408.

18. McNeil J, Helwig CC (2015) Balancing social responsibility and personal autonomy: adolescents' reasoning about community service programs. J Genet Psychol 176: 349-368.
Copyright: (02017 Se-Won K. This is an open-access article distributed under the terms of the Creative Commons Attribution License, which permits unrestricted use, distribution, and reproduction in any medium, provided the original author and source are credited. 